\title{
UMA CONTRIBUIÇÃO NOTÁVEL PARA A GEOGRAFIA DA COLONIZAÇÃO
}

\author{
SUZANNE DAVEAU ${ }^{1}$
}

Terá sido o mundo tropical, e a África em particular, um «objecto de pesquisa quase por acidente e sem grande continuidade» na obra do geógrafo Carlos Alberto Medeiros? Foi o que escreveu recentemente Teresa Barata Salgueiro na Apresentação do livro que colegas e discípulos lhe dedicaram na altura da sua aposentação. Parece bem que sim, quando se nota que o essencial das publicações dele sobre temas de Geografia tropical data dos anos 70 do século XX. Mas este facto indesmentível não impede que um dos seus livros cientificamente mais importantes e originais continue a ser a dissertação de doutoramento, defendida em 1976, sob o título de A Colonização das Terras Altas da Huíla (Angola). Estudo de Geografia Humana.

Os sobressaltos políticos nacionais e mundiais que decorriam quando escrevia a tese e o catastrófico período de guerras intestinas, que assolou durante os decénios mais recentes a maior parte das antigas colónias portuguesas, tornaram, de repente, uma lúcida análise geográfica da colonização portuguesa no Sul de Angola numa obra que pode parecer ter sido reduzida logo a um "valor arqueológico» e tocada por um "amargo sabor a cinza», como escreveu em 1978 outro grande especialista da colonização portuguesa, o historiador René Pélissier. E ele acrescentou, com dúvida e mágoa: «Quem lerá este admirável livro em Lisboa»?

Pode tentar responder-se a esta pergunta ou a outra, quase idêntica: «Quem terá lido, até hoje, este grande livro em Portugal e na África?», quer entre os geógrafos e historiadores, quer entre os políticos e administradores encarregados do destino do povo português e dos povos africanos? Os arquivos do Centro de Estudos Geográficos de Lisboa permitem esclarecer, numa certa medida, esta dúvida. A tiragem inicial da obra foi de mil exemplares, dos quais apenas duas centenas continuam à espera de difusão. Cerca de 400 foram distribuídos pelo autor nos primeiros meses. Mais tarde, a difusão adquiriu um ritmo bastante regular, da ordem de 13 por ano em média durante o primeiro decénio

1 Investigadora do Centro de Estudos Geográficos, Universidade de Lisboa. E-mail: sdaveau@clix.pt 
e de uma dezena por ano durante o decénio mais recente, sem nenhum indício de estar actualmente a afrouxar. O facto de grande parte da difusão estar assegurada por uma empresa comercial impede, infelizmente, conhecer o destino geográfico e institucional dos livros vendidos. De qualquer modo, verifica-se a manutenção do interesse, em ritmo moderado mas contínuo, o que sugere uma utilização quantitativamente não negligenciável e provavelmente de bom nível, atendendo à especialização do tema e a sua não inclusão nos assuntos largamente difundidos pela actualidade mediatizada.

A Colonização das Terras Altas da Huíla apresenta-se como um grosso volume com cerca de 700 páginas. Dimensão que não deve meter medo ao leitor. É uma obra de grande clareza, nítida construção e leitura fácil. Extensos resumos em francês e inglês ajudam a uma primeira aproximação, bem como a pormenorizada análise crítica que Raquel Soeiro de Brito lhe dedicou na Finisterra, em 1977. O estudo foi realizado em pouco tempo e de uma vez. A recolha e o tratamento da informação, a redacção e a impressão do livro ocuparam menos de 6 anos no total, durante os quais o autor nunca deixou de cumprir as suas obrigações docentes. Um ritmo que traduz uma enorme e segura capacidade de trabalho, que lhe permitiu dominar e ultrapassar a novidade e complexidade do tema tratado, bem como a dispersão e variedade das fontes de informação disponíveis. A qualidade arquitectural e redaccional da obra denuncia uma segura e clássica formação metodológica, bem cedo adquirida.

Este estudo de Geografia humana é, fundamentalmente, uma análise de tema (um tipo de colonização original), estudado em determinado quadro regional, o das terras altas do Sul de Angola. O autor começou portanto, logicamente, por apresentar o desenrolar das fases sucessivas do fenómeno estudado, não sem o ter inserido previamente no seu quadro geográfico, físico e humano. René Pélissier (1978) considerou com razão esta primeira metade do livro como «um estudo muito importante de História regional», dedicado a um fenómeno único na África negra: «a implantação conseguida (até 1975) de uma sociedade rural branca e pobre, num mundo bantu e arcaico».

Depois de sólida e exaustiva análise das motivações e fases da colonização, o autor resumiu as características destas nas 15 páginas de um vigoroso e penetrante remate. O fenómeno da colonização explica-se pela complexa interferência de dados mais ou menos permanentes, cruzados com circunstâncias fortuitas. Entre outros: a necessidade política para Portugal de assegurar a efectiva ocupação de territórios longínquos de que reivindicava a posse; um clima aparentemente sedutor mas, na realidade, pouco propício a qualquer forma de agricultura rentável; a incursão dos Boers, entre 1880 e 1928; a aparição ou promoção de potenciais colonos rurais, brancos e pobres, sucessivamente originários de Pernambuco, da Madeira, dos Açores e do Norte de Portugal. Não menos determinantes foram a decisão de ligar preferencial e dificultosamente o recinto do planalto da Huíla à «boca de sertão» marítima e desértica de Moçamedes, de preferência ao coração povoado do grande pla- 
nalto, situado mais ao norte, em redor ao Huambo, e a presença de uma população pouco numerosa de pastores, mas irrequietos, com modo de vida arcaico e relutantes a qualquer assimilação. Afinal, a projectada colonização camponesa, utopicamente copiada de um modelo pátrio, tradicional e ultrapassado, apenas ia conhecer tardio desenvolvimento na forma de uma reduzida área de influência urbana, fracamente animada por um núcleo administrativo de cariz provinciano.

Será apenas depois de sólida colocação dos problemas e das possíveis linhas de interpretação, que o autor apresentará, na segunda parte do livro, a análise mais aprofundada dos principais aspectos da vida regional. Os dados demográficos serão sucintamente tratados, porque as estatísticas acessíveis não permitiam um desdobramento temporal, espacial e étnico suficiente para as tornar realmente úteis. Mais importância será concedida ao estudo das duas componentes principais da paisagem regional: o mato e o campo. Serão sucessivamente apresentadas a vida rural dos colonos e a dos indígenas, nas suas modalidades específicas e na sua diversidade. Sem esgotar temas muito complexos e que teriam exigido muito mais tempo para serem aprofundados, o autor mostrou bem a justaposição de formas de utilização do solo muito diversas, pouco coordenadas e bastante instáveis. Mostrou também que os colonos tiravam, na altura em que realizou o seu estudo, o essencial dos seus recursos não da agricultura mas do comércio com os indígenas, praticado na cidade ou em cantinas dispersas pelo mato. Difíceis e numerosos eram os problemas levantados por este teimoso empreendimento de colonização rural, já então meio fracassado. Em 1998, Mariano Feio irá lembrar, para o conjunto dos colonatos instalados por Portugal nos planaltos angolanos, que eles estavam inelutavelmente votados ao fracasso, por os seus organizadores não terem tomado em conta uma noção muito simples, mas fundamental: «era imperativo que as explorações dos colonos fossem rentáveis».

Relativamente aos empreendimentos que se sucederam nas Terras Altas da Huíla, Carlos Alberto Medeiros esforçou-se por identificar e analisar os problemas que iam surgindo e por propor «algumas perspectivas de evolução». Mas o descalabro que começava a desconjuntar Angola, na altura em que acabava de escrever o livro, deixa evidentemente transparecer certo desânimo, perante a amplidão dos insolúveis problemas acumulados.

A última parte do livro é consagrada ao estudo monográfico do fenómeno geográfico sem dúvida mais vivo da região: a cidade de Sá da Bandeira surgida, em poucos decénios, a partir da aldeia rural do Lubango (com 8000 habitantes nos anos 40, $15000 \mathrm{em} \mathrm{1960,} 31000 \mathrm{em} \mathrm{1970).} \mathrm{Sobre} \mathrm{este} \mathrm{centro} \mathrm{urbano}$ enquistado num mato pouco ocupado, afastado e pobre, pode deixar-se a palavra a Orlando Ribeiro (1981: 126), que o visitou duas vezes: em 1935, quando «tinha a atraente aparência de uma cidadezinha do Norte, a que não faltava o coreto no meio do jardim», e em 1969, quando «enchendo pouco a pouco de edificios pretensiosos», tinha já criado «um ambiente de intriga e maledicência.» Não menos incisivo em relação à cidade foi o próprio Carlos 
Alberto Medeiros, evocando, desde as primeiras linhas do prefácio da sua tese, «os pretos da região», que «aparecem com frequência pela cidade, perfeitamente desambientados, alheios, marginalizados, com os seus trajes tradicionais rudimentares».

Foi neste pequeno centro urbano enquistado e sem perspectivas que o governo português teimou em instalar tardiamente uma Faculdade de Letras, que incluía o ensino da Geografia, assegurado a partir de 1970 por três jovens assistentes formados em Lisboa. A criação desta antena universitária isolada tinha sido pensada «para estudantes brancos, filhos dos colonos ou de funcionários», e preferida à colocação de um centro de irradiação cultural, mais robusto e viável, na própria capital angolana ou no Huambo (RibeIRo, 1979: 281). Um dos poucos frutos desta absurda decisão foi, sem dúvida, o valioso livro escrito por Carlos Alberto Medeiros sobre as Terras Altas da Huíla. Mas a sua curta experiência angolana deixou-lhe, por certo, a amarga sensação de um retumbante fracasso, do qual não tinha a menor responsabilidade.

Tornou-se impossível, durante muitos anos, trabalhar cientificamente em Angola. Mesmo para um "filho da terra», como o geógrafo Ilídio do Amaral, mesmo para um teimoso historiador como René Pélissier, que traçou com mão de mestre, em dois livros (1977 e 1978), a história recente de Angola. Carlos Alberto Medeiros deu conta destes livros na Finisterra, em 1979, frisando que este trabalho histórico fundamental continha «algumas magníficas páginas de Geografia política, económica e social». Em 1989, ao despedir-se das investigações históricas que consagrava desde 1961 às antigas colónias africanas de Portugal, René Pélissier dedicou as suas pioneiras obras às jovens nações, que estavam então penosamente a nascer.

O mesmo destino se deve desejar à obra mestra de Carlos Alberto Medeiros, que nunca deixou de prestar discreto apoio aos centros universitários africanos, nascidos de tardio germe lusitano. Nem ele, nem a mulher Isabel Marques Medeiros, deixaram de dar a indispensável atenção à larga cintura tropical do Globo, tão importante para o seu equilíbrio de conjunto, mas tão frequentemente esquecida e menosprezada. Testemunham isso os artigos recentes que Carlos Alberto Medeiros consagrou, em 1999, à obra de Ilídio do Amaral, o seu iniciador em estudos angolanos, e, em 2001, à de Pierre Gourou, o grande geógrafo que elaborou o seu notável conceito interpretativo da Geografia humana a partir da análise dos problemas dos "países tropicais», prosseguida durante toda a sua longa vida. Insuficientemente conhecida em Portugal, a obra tropical de Carlos Alberto Medeiros é um dos apoios seguros que a inteligência portuguesa legou ao futuro angolano, que se espera feliz e, finalmente, pacífico. 


\section{Obras citadas:}

1976 - Carlos Alberto Medeiros - A Colonização das Terras Altas da Huíla (Angola). Estudo de Geografia Humana. Memórias do Centro de Estudos Geográficos, 2, Lisboa.

1977 - CARlos Alberto Medeiros - Le phénomène de la colonisation et quelques problèmes de la mise en valeur du Sud-Ouest de l'Angola», Revue Canadienne des Études Africaines, Québec, 11(1): 69-83

1977 - Raquel Soeiro de Brito - Acerca da colonização das Terras Altas da Huíla (Angola), Finisterra - Revista Portuguesa de Geografia, XII (24): 298-309.

1977 - RenÉ PéLISsIER - Les Guerres Grises. Résistance et Révoltes en Angola (1845-1941), Pélissier, Orgeval.

1978a - RenÉ PÉLISSIER - La Colonie du Minotaure. Nacionalismes et Révoltes en Angola (1926-1961), Pélissier, Orgeval.

1978b - René PÉLISsier - A Colonização das Terras Altas da Huíla (Angola) por Carlos Alberto Medeiros. Revue Française d'Études Politiques Africaines, 147, Paris, p. 69.

1979 - Carlos Alberto Medeiros - Dois livros sobre a história recente de Angola. FinisterraRevista Portuguesa de Geografia, XIV (27): 87-96.

1979 - ORlando Ribeiro - Décolonisation, enseignement et recherche scientifique. Colóquio sobre Educação e Ciências Humanas na África de Língua Portuguesa, 20-22 de Janeiro de 1975, Fundação Calouste Gulbenkian, Lisboa, 1979: 281-286.

1981 - Orlando Ribeiro - A Colonização de Angola e o seu Fracasso, Estudos Portugueses, Imprensa Nacional - Casa da Moeda, Lisboa.

1989 - RenÉ PÉLISSIER - Naissance de la Guiné. Portugais et Africains en Sénégambie (1841-1936), Pélissier, Orgeval.

1998 - Mariano Feio - As Causas do Fracasso da Colonização Agrícola de Angola, Comunicações, 7, Instituto de Investigação Científica Tropical, Lisboa.

1999 - Carlos Alberto Medeiros - Homenagem a Ilídio do Amaral. Finisterra - Revista Portuguesa de Geografia, XXXIV (67-68): 5-9.

2001 - Carlos Alberto Medeiros - Pierre Gourou (1900-1999). Finisterra-Revista Portuguesa de Geografia, XXXVI (71): 45-48.

2002 - Teresa Barata Salgueiro - Apresentação. Olhares sobre o Terrrtório e a Espacialidade, Estudos de Geografia Humana e Regional, Centro de Estudos Geográficos, Lisboa, 45: 5-8. 